\section{Pneumocephalus following attempted epidural anaesthesia}

Karen M. Ash MD FRCSC, John E. Cannon MD FRCPC, Diane R. Biehl MD FRCPC
This report describes iatrogenic pneumocephalus in an obstetrical patient following attempted epidural annesthesia using the loss of resistance technique. On the fourth attempt at epidural injection, an apparent loss of resistance was identified and $5 \mathrm{ml}$ air was injected. The patient complained immediately of severe bifrontal headache followed by emesis. The baby was eventually delivered by Caesarean section, with general anaesthesia and avoiding nitrous oxide. The patient's headache resolved within $24 \mathrm{hr}$ without further sequelae.

Cette histoire de cas décrit la création d'un pneumoencéphale iatrogene chez une patiente obstétricale après une tentative d'anesthésie épidurale urilisant la technique de perte de résistance. A la quatrième tentative d'injection épidurale, une perte de résistance apparente fut identifée et $5 \mathrm{ml}$ d'air furem injectés. La patiente s'est plainte immédiatement de céphalée bifrontale sévère suivit de vornissements. Le bébé fut éventuellement accouché par une césarienne sous une anesthésie générale évitant le protoxyde d'azote. La céphalée a disparue en dedans de 24 heures sans autres séquelles.

Since the first description of epidural anaesthesia by Corning in 1885, ' numerous methods for the identification of the epidural space have been proposed. The "loss of resistance" technique (LOR) jointly credited to Forestier and Sicard ${ }^{2,3}$ remains popular. Confirmation of entry into the epidural space, as the name implies, occurs upon recognition of the sudden release of resistance, usually of

\section{Key Words}

ANAESTHESIA: obstetric;

ANAESTHETIC TECHNIQUES: epidural;

COMPLICATIONS: pneumocephalus.

From the Department of Obstetrics and Gynecology and the Department of Anaesthesia, University of Manitoba and St. Boniface General Hospital, Winnipeg, Manitoba, Canada.

Address correspondence to: Dr. K. M. Ash, Department of Obstetrics and Gynecology, St. Boniface General Hospital, 409 Tache Avenue, Winnipeg, Manitoba, Canada R2H 2 A6. Accepted for publication 3rd May, 1991 air as the advancing needle emerges from the ligamentum flavum. Despite the many advantages of epidural anaesthesia, complications do occur. Hypotension, local anaesthetic toxicity, total spinal anaesthesia, and inadvertent dural puncture are well-known hazards.

We wish to report a case of pneumocephalus following attempted identification of the epidural space by the loss of resistance technique, in the absence of overt evidence of dural puncture.

\section{Case Report}

A 29-yr-old female, gravida 2, para 0, was admitted to the labour and delivery suite in spontaneous labour at $39 \mathrm{wk}$. The pregnancy had been uneventful except for one episode of scant vaginal bleeding in the first trimester. Her past medical history included a cholecystectomy and therapeutic abortion. Physical examination of the head and neck, chest and cardiovascular system was within normal limits. Uterine contractions of moderate intensity were palpable every four minutes. A fetal heart rate of 140 beats per minute with no decelerations was recorded. Pelvic examination revealed an effaced cervix, 2 to $3 \mathrm{~cm}$ dilated, with a cephalic presentation at -2 station. Parenteral narcotic analgesia was given at $4 \mathrm{~cm}$ dilatation following artificial rupture of the membranes. Augmentation of labour with syntocinon was implemented for uterine inertia. Further requests for analgesia prompted attempts at establishing epidural anaesthesia.

With the patient in the sitting position, the back was prepared and draped in an aseptic fashion, and $2 \%$ lidocaine was infliltrated for skin analgesia. Three attempts were made with a 16 gauge disposable Tuohy needle (EN-9000 16GT $\times 9 \mathrm{~cm}$, Vas-Cath Canada Limited, Mississauga, Ontario, Canada) at the $\mathrm{L}_{3-4}$ and $L_{2-3}$ levels, but they were unsuccessful due to contact with bone. A fourth attempt was made with a 16 gauge disposable epidural needle (Monoject 222 16T $\times 3 \frac{1}{2}$ Hustead Point, Sherwood Medical, St. Louis, Missouri, USA) at the $\mathrm{L}_{2-3}$ level, with an apparent superficial loss of resistance. Approximately $5 \mathrm{ml}$ of air was injected and immediately the patient complained of a severe bifrontal headache with occipital radiation. No cerebrospinal fluid was observed, and, as the headache did not abate, the needle was removed after one minute. The discomfort did 


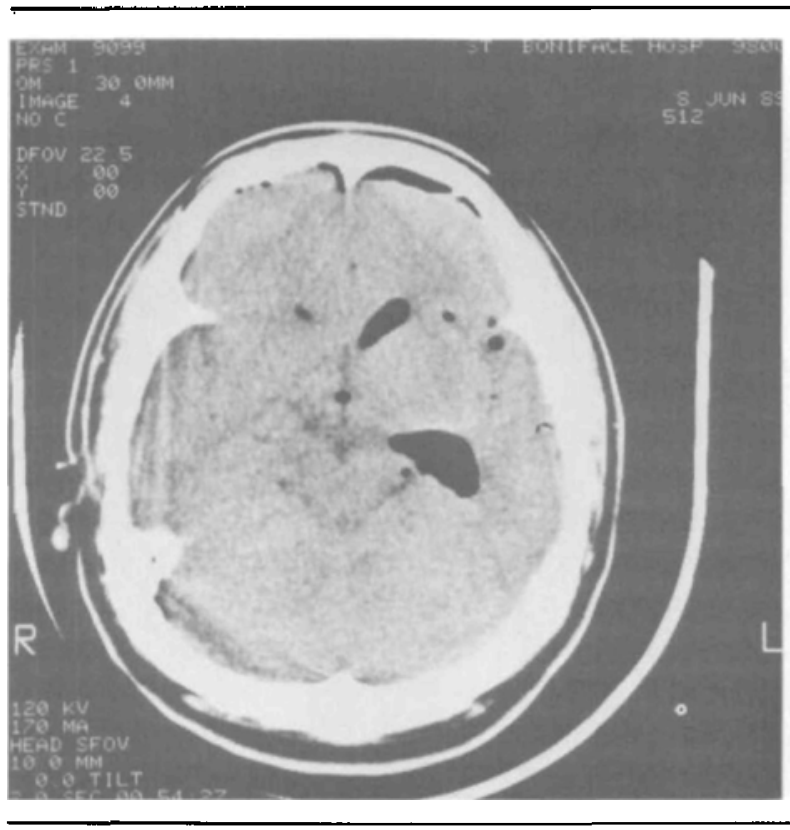

FIGURE 1 Computed tomography of the cranium demonstrating air in the ventricles and subarachnoid space.

not resolve with the patient lying supine. Several episodes of violent emesis followed. No change in the patient's level of consciousness was observed and no focal neurological deficit could be demonstrated. No further attempts to establish epidural anaesthesia were made.

The patient's unremitting headache prompted concern for an incidental subarachnoid haemorrhage or pneumocephalus, and a neurosurgical consultation was obtained. The consultant's examination of the patient was completely normal and a postpartum computerized tomographic (CT) scan of the brain was recommended. Analgesia was provided with morphine, and the patient's labour quickly progressed to full dilatation.

A persistent occiput posterior position at -1 station prompted Caesarean section which was performed under general anaesthesia without difficulty. Nitrous oxide was not used. A live born female infant, $3230 \mathrm{~g}$, was delivered in good condition, and was attended to by a paediatrician. The Apgar scores were eight at one minute and nine at five minutes. The neonate's course in hospital was uneventful.

By the first postoperative day, the mother's headache had resolved. A CT examination demonstrated air in the lateral ventricles and basal cisterns (see Figures 1, 2). The patient was mobilized slowly and complained of a headache upon standing, which abated during her hospital stay. She was discharged five days after the operation.

\section{Discussion}

Puncture of the dura is a known complication of epidural anaesthesia. Recognition of this event usually occurs

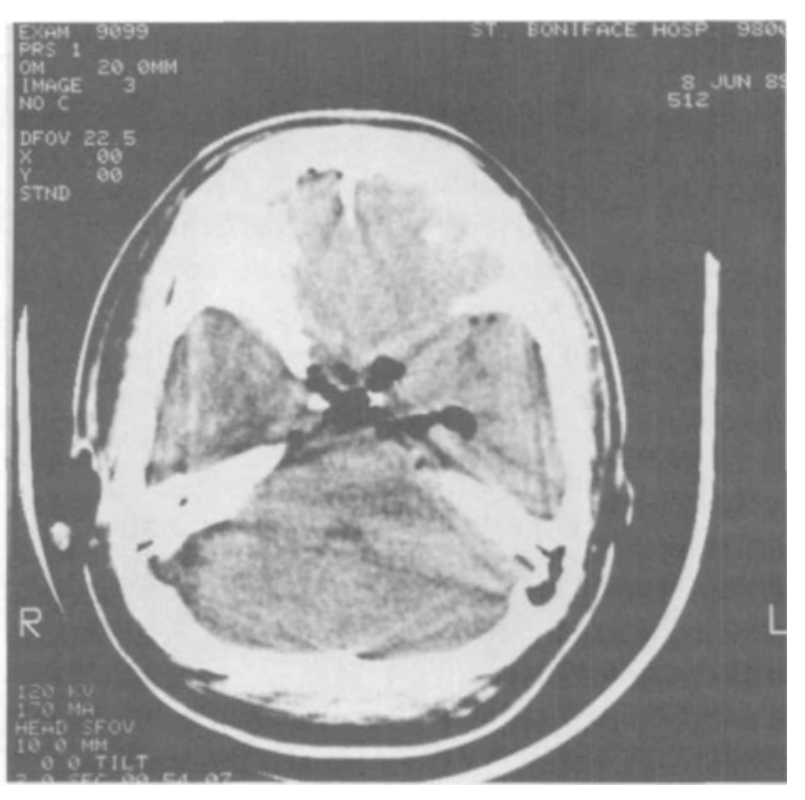

FIGURE 2 Computed tomography of the cranium demonstrating air in the basal cisterns.

when cerebrospinal fluid (CSF) is seen to egress from the hub of the needle at the site of entry. Alternatively, stretching of the meninges following CSF leakage after such a "wet tap" often leads to a headache one to three days later which alerts the physician to suspect a dural puncture.

Transient immediate headaches have been reported after attempted epidural anaesthesia using the loss of resistance technique. ${ }^{4.5}$ These events have been attributed to injection of air into the subarachnoid or subdural space with cephalad migration and irritation of the intracranial meninges. Attempts have been made to confirm this occurrence radiographically on upright lateral roentgenograms of the skull with some success. ${ }^{4}$ A recent report described an obstetrical patient who suffered a total spinal anaesthetic after an inadvertant dural puncture during an epidural anaesthetic using the loss of resistance technique. ${ }^{6} \mathrm{~A}$ delay in neurological recovery prompted a CT scan, which revealed a pneumocephalus. Due to the critical nature of the patient's illness, a headache, if present, was not a prominent feature of the case history.

Our patient experienced a similar headache during attempted epidural anaesthesia during labour. A cranial CT scan revealed the presence of air in the lateral ventricles and basal cisterns, thereby confirming pneumocephalus. No CSF leakage was noted, which is in keeping with other reports. ${ }^{4,6} \mathrm{~A}$ rapid onset of symptoms, especially when the patient is upright, was also observed in our patient and in others reported. ${ }^{4,5}$ Unlike other reports, our patient did not obtain relief from her 
symptoms by lying down. No persistant morbidity occurred.

This case illustrates iatrogenic pneumocephalus following attempted epidural catheter insertion using the loss of resistance technique. Presumably, this complication is avoidable if preservative-free saline rather than air is used to identify the epidural space. Physicians continuing to use the LOR technique should be aware of this complication. Amelioration of the symptoms may be afforded by administration of $100 \%$ oxygen to promote reuptake of nitrogen from the collection of air. ${ }^{5}$ It is controversial whether patients undergoing air pneumoencephalography should be given nitrous oxide if general anaesthesia is required, because of the potential pressure effects of nitrous oxide in a close space like the cranium. ${ }^{7}$ Some authors believe nitrous oxide is contraindicated ${ }^{8}$ and we avoided its use during the general anaesthetic for this patient's Caesarean section.

This case report re-emphasizes the possibility of pneumocephalus following attempted epidural anaesthesia. We suspect that this complication may occur more frequently than is commonly recognized. The diagnosis can be easily confirmed with computerized tomography. No permanent sequelae were observed.

\section{References}

1 Cousins MJ, Bridenbaugh PO. Neural Blockade in Clinical Anesthesia and Management of Pain. 2nd ed. Philadelphia: JB Lippincott, 1988: 7.

2 Adriani J. Labat's Regional Anesthesia: Techniques and Clinical Applications. 4th ed. St Louis: WH Green, 1985: 701.

3 Sicard JA, Forestier J. Radiographic method for exploration of the extradural space using lipidol. Rev Neurol (Paris) 1921; 28: 1264.

4 Abram SE, Cherwenka $R W$. Transient headache immediately following epidural steroid injection. Anesthesiology 1979; 50: 461-2.

5 Ahlering $J R$, Brodsky $J B$. Headache immediately following attempted epidural analgesia in obstetrics. Anesthesiology 1980; 52: 100-1.

6 Katz Y, Markovits R, Rosenberg B. Pneumoencephalos after inadvertent intrathecal air injection during epidural block. Anesthesiology 1990; 73: 1277-9.

7 Wolfson B, Hetrick WD. Anesthesia for neuroradiologic procedures. In: Cottrell JE, Turndorf H (Eds.). Anesthesia and Neurosurgery. 2nd ed. St Louis: CV Mosby, 1986: 105.

8 Saidman $L$, Eger El. Change in cerebrospinal fluid pressure during pneumoencephalography under nitrous oxide anesthesia. Anesthesiology 1965; 26: 67-72. 